\title{
General practitioners' perceptions of their practice of evidence-based chronic disease prevention interventions: a quantitative study in Shanghai, China
}

Feng Fan ${ }^{1,2}$, Zhaoxin Wang ${ }^{3,4}$, Dehua Yu ${ }^{1,2,5}$, Chen Chen ${ }^{6}$, Delei Shen ${ }^{7}$, Zhaohu Yu ${ }^{8}$, Xin Liu ${ }^{3}$, Huining Zhou ${ }^{3}$ and Jianwei Shi ${ }^{1,3^{*}}$

\begin{abstract}
Background: Epidemic chronic diseases pose significant challenges to the improvement of healthcare in China and worldwide. Despite increasing international calls for the inclusion of evidence-based decision-making (EBDM) processes in chronic disease prevention and control programming as well as policymaking, there is relatively little research that assesses the current capacity of physicians and the factors that influence that capacity in China.

Method: This cross-sectional study was conducted in community health centres (CHCs) in Shanghai, China, using multistage cluster sampling. An evidence-based chronic disease prevention (EBCDP) evaluation tool was employed to assess physician EBCDP awareness, adoption, implementation and maintenance based on the Reach, Effectiveness, Adoption, Implementation and Maintenance (RE-AIM) framework and using a 7-point Likert scale. Linear regression analysis was used to assess associations between each EBCDP aspect and overall EBCDP status with participant characteristics or organizational factors.

\footnotetext{
* Correspondence: shijianwei_amy@126.com

'Yangpu Hospital affiliated to Tongji University School of Medicine, Shanghai 200090, China

${ }^{3}$ School of Public Health, Shanghai Jiaotong University School of Medicine, Shanghai 200025, China

Full list of author information is available at the end of the article
}

(c) The Author(s). 2020 Open Access This article is licensed under a Creative Commons Attribution 4.0 International License, which permits use, sharing, adaptation, distribution and reproduction in any medium or format, as long as you give appropriate credit to the original author(s) and the source, provide a link to the Creative Commons licence, and indicate if changes were made. The images or other third party material in this article are included in the article's Creative Commons licence, unless indicated otherwise in a credit line to the material. If material is not included in the article's Creative Commons licence and your intended use is not permitted by statutory regulation or exceeds the permitted use, you will need to obtain permission directly from the copyright holder. To view a copy of this licence, visit http://creativecommons.org/licenses/by/4.0/. The Creative Commons Public Domain Dedication waiver (http://creativecommons.org/publicdomain/zero/1.0/) applies to the data made available in this article, unless otherwise stated in a credit line to the data. 


\begin{abstract}
(Continued from previous page)
Result: A total of 892 physicians from CHCs in Shanghai, China, were assessed. The physicians perceived their awareness (mean $=4.90, \mathrm{SD}=1.02$ ) and maintenance (mean $=4.71, \mathrm{SD}=1.07$ ) of EBCDP to be relatively low. Physicians with relatively lower job titles and monthly incomes (>9000 RMB) tended to have relatively higher scores for the awareness, adoption, and implementation of EBCDP $(P<0.05)$. Those who had participated in one program for chronic disease prevention and control were less likely to adopt $(b=-0.284, P=0.007)$, implement $(b=-0.292, P=0.004)$, and maintain $(b=-0.225, P=0.025) E B C D P$ than those who had participated in more programs. Physicians in general practice (Western medicine) had a lower level of awareness of EBCDP than those in other departments $(P<0.0001)$. Physician from CHCs located in suburban areas had lower scores for awareness $(b=$ $-0.150, P=0.047)$, implementation $(b=-0.171, P=0.029)$, and maintenance $(b=-0.237, P=0.002)$ that those from urban CHCs. Physicians in CHCs affiliated with universities had higher scores on all four EBCDP aspects that those in CHCs not affiliated with a university.

Conclusions: This study provides quantitative evidence illustrating EBCDP practices among physicians in CHCs with various personal and organizational characteristics, respectively. More methods should be provided to increase the awareness of such physicians regarding EBCDP to stimulate the use of EBCDP for their patients and in connection with other public health priorities.
\end{abstract}

Keywords: General practitioner, Evidence-based, Implementation, China

\section{Background}

Epidemic chronic diseases pose significant challenges for healthcare worldwide [1]. According to NCD Countdown 2030, chronic diseases accounted for approximately 40.5 million of the 56.9 million deaths that occurred worldwide in 2016 [2]. In China too, chronic diseases, including stroke, ischemic heart disease, lung cancer, and chronic obstructive pulmonary disease (COPD), are widespread. Data indicate that stroke and ischaemic heart disease were the leading causes of death and decreased disability-adjusted life years (DALYs) at the national level in China in 2017 [3]. Against this background, the efficient global prevention and control of chronic disease has gradually become a focus for scholars $[4,5]$. In China, the prevention and control of chronic diseases has been included in the Healthy China 2030 Strategic Plan. Evidence-based chronic disease prevention (EBCDP) has emerged and become widely known as a scientific tool to increase efficiency in preventing and controlling chronic disease in developed countries [6]. Evidence-based tools are utilized by health practitioners in many countries. In the US, the web portal Cancer Control P.L.A.N.E.T., which is designed to support cancer control initiatives, presents useful approaches for planning and developing evidence-based programs and policies [7-10]. In Australia, public health resource Health-Evidence.org has been the widely accepted and used by public health practitioners and the public [11]. In addition, in Australia and the US, the Cochrane Collaboration is a commonly used repository of evidence from systematic reviews [12, 13].

Currently, studies have begun to assess the extent and possible influencing factors of the implementation and dissemination of EBCDP, which is a dynamic program that involves awareness, adoption, implementation and maintenance [14]. Hannon et al. found that US cancer control practitioners had strong preferences regarding cancer control programs, but only $48 \%$ of the practitioners had used evidence-based practice resources [15]. Interviewing New York state local health department leaders, Sosnowy et al. found that although most of these individuals understood the EBP concept, relatively few had substantial expertise and experience with it [16]. Qualitative studies have shown that possible influencing factors include strong leadership, workforce capacity (i.e., numbers and skills), resources, funding and program mandates, political support, and access to data and program models suitable for community conditions $[14,16]$. In recent years, studies have quantitatively revealed a possible relationship between the application of evidence-based decision-making (EBDM) and the factors influencing it, primarily based on analyses performed in the US, Australia, and Canada $[17,18]$. These studies have focused on personal and organizational-level barriers to and facilitators of EBCDP. Common barriers to EBCDP include a lack of time, a lack of skills and formal training, a lack of incentives to use evidence when making decisions, a lack of funding, and an unsupportive organizational culture [19-24]. Budd et al. (2018) studied organizational and contextual factors that affect the adoption of evidencebased chronic disease interventions in the US and elsewhere [25].

Despite increasing international calls for the inclusion of EBDM in public health programming and policymaking [16, 26-29], few studies have systematically examined dynamic EBCDP practices and the factors influencing them. In lower- and middle-income countries, little quantitative information is available on the 
status of and factors related to these practices in primary care health institutions. For instance, in Shanghai, various intervention programs have targeted the prevention of chronic diseases, including diabetes, hypertension, and stroke, as required by public health plans in Shanghai [30]. However, there have been few studies that investigate how public health practitioners have implemented these programs and the possible factors influencing the different aspects of EBCDP.

By surveying physicians from community healthcare centres (CHCs) in Shanghai, this study quantitatively measured the implementation and dissemination of EBCDP programs in Shanghai and examined possible factors influencing the various processes involved in EBCDP from the perspective of the physician. In China, primary care health institutions are responsible for chronic disease prevention and control [10]. Therefore, we focused on $\mathrm{CHC}$ physicians.

\section{Methods \\ Source}

In this study, a multistage stratified cluster random sampling method was used to obtain a representative sample of physicians from CHCs in Shanghai. To make the sample comparable, a sample of CHCs was first collected randomly from $246 \mathrm{CHCs}$ in Shanghai in 2019. Using a random number generator, 39 urban and 39 suburban $\mathrm{CHCs}$ were chosen. Then, we asked the administrations of the $\mathrm{CHCs}$ to assist with the survey. Ultimately, 36 $\mathrm{CHCs}$ in the urban area and 39 in the suburban area agreed to help, for a total of $75 \mathrm{CHCs}$. According to the average proportional distribution of various physician job titles in CHCs in Shanghai, we then randomly selected 6 junior physicians, 6 mid-level physicians, and 1 senior physician in each $\mathrm{CHC}$. Finally, 975 questionnaires were provided to the participating physicians for completion between April and July 2019.

\section{Measurement \\ $E B C D P$ status}

To analyse the status of EBCDP and the factors influencing it in CHCs in China, we used Dreisinger et al.'s (2012) analytic framework [31-33]. According to this framework, decisions to adopt, accept and utilize an innovation result from the following dynamic process [14]: (1) awareness, which involves defining the actions taken to make target audiences aware of the innovative programs across sites and settings [32]; (2) adoption, which is the absolute number, proportion, and representativeness of institutions and practitioners who deliver a program; (3) implementation, which is the extent to which an innovation is completely executed, accounting for adaptation and costs [34]; (4) maintenance, which is the extent to which a program becomes institutionalized or part of routine organizational practices and policies [32].
We used a survey tool developed by the Prevention Research Center in St. Louis and the Missouri Foundation for Health to facilitate the dissemination of prevention interventions across the US state of Missouri [31]. All the items are measured on a 7-point Likert scale, with "1" and "7" representing "strongly disagree" to "strong agree", respectively. We examined the reliability and validity of the evaluation tool and modified it according to the test results. The coefficient of one item (i.e., the community served by the intervention considers a certain disease to be a problem) on the overall scale was below 0.30 . Therefore, this item was deleted, and 19 items remained. We found that the reliability and validity of the scale were acceptable. The Cronbach's $\alpha$ of the total scale was 0.981 , and the Spearman-Brown coefficient was 0.924 . For the subscales, the Cronbach's $\alpha$ values were $0.865,0.959,0.965$ and 0.970 , and the Spearman-Brown coefficients were 0.631, 0.950, 0.957 and 0.918 for the subscales of awareness, adoption, implementation, and maintenance, respectively. All these results indicated that the scale had satisfactory applicability for physicians from $\mathrm{CHCs}$ in China. The questionnaires were sent via web mail, and written informed consent was obtained from all participants.

\section{Possible influencing factors}

We included personal and organizational characteristics as the primary factors in this study. The personal factors were sex, age, education, position, working years, and monthly income. The organizational factors were the number of programs for chronic disease prevention and control a physician had participated in, department, $\mathrm{CHC}$ location (i.e., urban or suburban), and whether the $\mathrm{CHCs}$ were affiliated with universities. The number of programs for chronic disease prevention and control variable concerns the number of such programs the surveyed physicians had participated in. The included departments were general medicine (Western medicine), prevention and health care, general practice in traditional Chinese medicine, and other departments, such as medical technology and rehabilitation. We compared the $\mathrm{CHC}$ locations (urban vs. suburban) because we desired to uncover regional differences. In an urban region, there is a dense distribution of residents as well as secondary and tertiary hospitals. Thus, in such regions, there may be more investment in training programs or chronic disease prevention programs involving EBCDP for physicians. In a suburban region, because there are fewer secondary and tertiary hospitals, more efforts are devoted to the provision of medical healthcare by physicians instead of chronic disease prevention and control [35]. EBCDP practice may be impacted by this factor. Regarding the $\mathrm{CHC}$-university affiliation variable, $\mathrm{CHC}$ affiliation with a university indicates the availability of 
more evidence-based resources, including literature resources and training from researchers at these universities [36].

\section{Statistical analysis}

All statistics were performed using SAS 9.0. Descriptive analysis was used to describe participant characteristics and the factors that possibly influenced EBCDP practice. T-tests and ANOVA were used to analyse the different factors affecting the various EBCDP aspects, including awareness, adoption, implementation, maintenance, and overall EBCDP status. Finally, we used linear regression to examine the relationship between independent variables, including the personal and organizational factors and the dependent variables of each EBCDP aspect (awareness, adoption, implementation and maintenance) and overall EBCDP status.

\section{Results}

\section{Participant demographics}

Table 1 provides descriptions of the physicians and $\mathrm{CHCs}$ investigated in this study. A total of 892 valid questionnaires were collected from $75 \mathrm{CHCs}$. The effective response rate was $91.49 \%$. The percentages of males $(49.10 \%)$ and females $(50.90 \%)$ were similar. The largest proportion of physicians was in the 31-40 year age group (46.97\%). The majority of the participants had bachelor's degrees (77.69\%). Most of the physicians held junior $(46.63 \%)$ and mid-level $(45.74 \%)$ titles and had worked for $\leq 5$ years (36.38\%). The largest proportion (43.16\%) earned monthly incomes of 6001-9000 RMB. Regarding the number of chronic disease prevention and control programs, $33.63 \%$ of the physicians had participated in 1 program, and $19.73 \%$ had taken part in $\geq 5$ programs. Concerning departmental affiliation, most physicians were in general medicine (Western medicine) (53.59\%). More physicians were from $\mathrm{CHCs}$ located in urban areas (54.26\%), and a small proportion was from CHCs affiliated with a university (21.30\%).

The $\mathrm{CHC}$ physicians scored lowest on the perception of their maintenance of EBCDP (mean $=4.71, \mathrm{SD}=1.07$ ), representing slightly agree. The score for EBCDP awareness was also relatively low (mean $=4.90, \mathrm{SD}=1.02$ ). Comparatively, the scores for adoption (mean $=5.05$, $\mathrm{SD}=1.10$, representing moderately agree) and implementation (mean $=5.00, \mathrm{SD}=1.07$, representing moderately agree) were higher. The overall EBCDP score was 4.869 , representing slightly agree.

\section{Effects of physician characteristics on EBCDP processes}

Table 2 shows the distribution of the scores for the EBCDP aspects stratified according to physician characteristics. Regarding the sex and age groups, there were no significant differences between the subgroups in their scores for the various EBCDP aspects. Concerning education, physicians with an associate's degree or lower were more likely to have a relatively higher score for maintenance $(P=0.046)$. Regarding the level of physician, compared with mid-level and senior physicians, junior physicians had higher scores for awareness $(P=0.018)$, adoption $(P=0.044)$, and implementation $(P=0.016)$. Regarding the number of programs, the results indicated that those who participated in one program had significantly lower scores for adoption than those who participated in more programs (mean $=4.939, P=0.042$ ). In addition, there were no significant differences between subgroups for the variables working years and income.

The organizational factors displayed stronger effects. Regarding the department, physicians from general medicine (Western medicine) had the lowest scores for awareness $($ mean $=4.816, P=0.0001)$, adoption $($ mean $=4.932, P<$ 0.0001 ), implementation (mean $=4.865, P<0.0001$ ), and maintenance (mean $=4.567, P<0.0001$ ). In terms of $\mathrm{CHC}$ location, in contrast to physicians at suburban $\mathrm{CHCs}$, physicians at urban $\mathrm{CHCs}$ had higher scores on all four of the aspects: 4.997 vs. 4.788 (urban VS suburb, $P=0.002$ ) for awareness, 5.169 vs $4.904(P=0.0003)$ for adoption, 5.124 vs. $4.842(P<0.0001)$ for implementation, and 4.867 vs. 4.526 $(P<0.0001)$ for maintenance. Last, the results indicated that physicians in university-affiliated $\mathrm{CHCs}$ had relatively higher scores for awareness $(P=0.020)$, adoption $(P=0.001)$, implementation $(P=0.001)$, and maintenance $(P<0.0001)$ than physicians at $\mathrm{CHCs}$ not affiliated with a university.

Regression analysis of EBCDP aspects and personal and organizational factors.

Linear regression was used to analyse the differences within the four EBCDP aspects based on various personal and organizational factors (Table 3). The results indicate that compared with the group aged $\leq 30$ years, physicians aged 31-40 years were less likely to maintain EBCDP $(b=-0.218, P=$ 0.036). There were no significant differences based on education level or years of work. Interestingly, lower level physicians had higher scores for the awareness, adoption, and implementation of EBCDP $(P<0.05)$. Compared with those who had a monthly income of $9000 \mathrm{RMB}$ per month, physicians with a monthly income $\leq 6000$ RMB (awareness: $\mathrm{b}=-0.255, P=0.011$; adoption: $\mathrm{b}=-0.217, P=0.042$; implementation: $\mathrm{b}=-0.229, P=0.027$ ) and 6001-9000 RMB (awareness: $\mathrm{b}=-0.247, P=0.011$; adoption: $\mathrm{b}=-0.204, P=0.049$; overall: $\mathrm{b}=-0.187, \mathrm{~b}=0.045$ ) had lower scores. Compared with physicians who participated in more than five programs, those who participated in one program had lower scores for adoption $(b=-0.284, P=0.007)$, implementation $(\mathrm{b}=-0.292, P=0.004)$, maintenance $(\mathrm{b}=-0.225$, $P=0.025)$ and overall EBCDP status $(\mathrm{b}=-0.244, P=0.010)$.

In terms of department, interestingly, we found that compared with general practice (Western medicine) physicians, those in other departments had higher scores for awareness $(b=0.505, P<0.0001)$, adoption, implementation, maintenance and overall $(P<0.0001)$. Concerning the areas in 
Table 1 Demographics and participant perceptions of the various aspects of EBCDP $(n=892)$

\begin{tabular}{|c|c|c|c|}
\hline Variable & Classification & $\mathrm{n}$ & $\%$ \\
\hline \multirow[t]{2}{*}{ Sex } & Male & 438 & 49.10 \\
\hline & Female & 454 & 50.90 \\
\hline \multirow[t]{4}{*}{ Age (year) } & $\leq 30$ & 194 & 21.75 \\
\hline & $31-40$ & 419 & 46.97 \\
\hline & $41-50$ & 240 & 26.91 \\
\hline & $>50$ & 39 & 4.37 \\
\hline \multirow[t]{3}{*}{ Education } & Associate's degree or below & 89 & 9.98 \\
\hline & Bachelor's degree & 693 & 77.69 \\
\hline & Master's degree or higher & 110 & 12.33 \\
\hline \multirow[t]{3}{*}{ Position } & Junior & 416 & 46.63 \\
\hline & Mid-level & 408 & 45.74 \\
\hline & Senior & 68 & 7.62 \\
\hline \multirow[t]{4}{*}{ Working years (years) } & $\leq 5$ & 322 & 36.38 \\
\hline & $6-10$ & 232 & 26.21 \\
\hline & $11-15$ & 153 & 17.29 \\
\hline & $>15$ & 178 & 20.11 \\
\hline \multirow[t]{3}{*}{ Income (RMB, Ұ) } & $\leq 6000$ & 344 & 38.57 \\
\hline & $6001-9000$ & 385 & 43.16 \\
\hline & $>9000$ & 163 & 18.27 \\
\hline \multirow[t]{5}{*}{ Number of chronic disease prevention and control programs } & 1 & 300 & 33.63 \\
\hline & 2 & 131 & 14.69 \\
\hline & 3 & 155 & 17.38 \\
\hline & 4 & 130 & 14.57 \\
\hline & $\geq 5$ & 176 & 19.73 \\
\hline \multirow[t]{4}{*}{ Department } & General medicine (Western medicine) & 478 & 53.59 \\
\hline & Prevention and health care & 228 & 25.56 \\
\hline & General practice (Chinese medicine) & 91 & 10.20 \\
\hline & Other departments & 95 & 10.65 \\
\hline \multirow[t]{2}{*}{ Area } & Urban & 484 & 54.26 \\
\hline & Suburban & 408 & 45.74 \\
\hline \multirow[t]{2}{*}{ Affiliated with a university } & Yes & 190 & 21.30 \\
\hline & No & 702 & 78.70 \\
\hline Awareness $(X \pm S)$ & & 4.902 & 1.022 \\
\hline Adoption $(X \pm S)$ & & 5.048 & 1.097 \\
\hline Implementation $(X \pm S)$ & & 4.995 & 1.073 \\
\hline Maintenance $(X \pm S)$ & & 4.711 & 1.066 \\
\hline Overall EBCDP status $(X \pm S)$ & & 4.869 & 0.998 \\
\hline
\end{tabular}

which the CHCs were located, compared with urban $\mathrm{CHC}$ physicians, physicians from suburban $\mathrm{CHCs}$ had lower scores for awareness $(b=-0.150, P=0.047)$, implementation $(\mathrm{b}=-0.171, P=0.029)$, maintenance $(\mathrm{b}=-0.237, P=$ $0.002)$, and overall $(b=-0.192, P=0.008)$. Physicians in $\mathrm{CHCs}$ affiliated with a university had higher scores for adoption $(b=-0.241, P=0.011)$, implementation $(b=-$
$0.224, P=0.015)$, maintenance $(\mathrm{b}=-0.321, P=0.0001)$ and overall $(\mathrm{b}=-0.257, P=0.003)$.

\section{Discussion}

Over the past several years, many efforts have been devoted to developing EBDM and promoting its implementation among public health practitioners in developed 


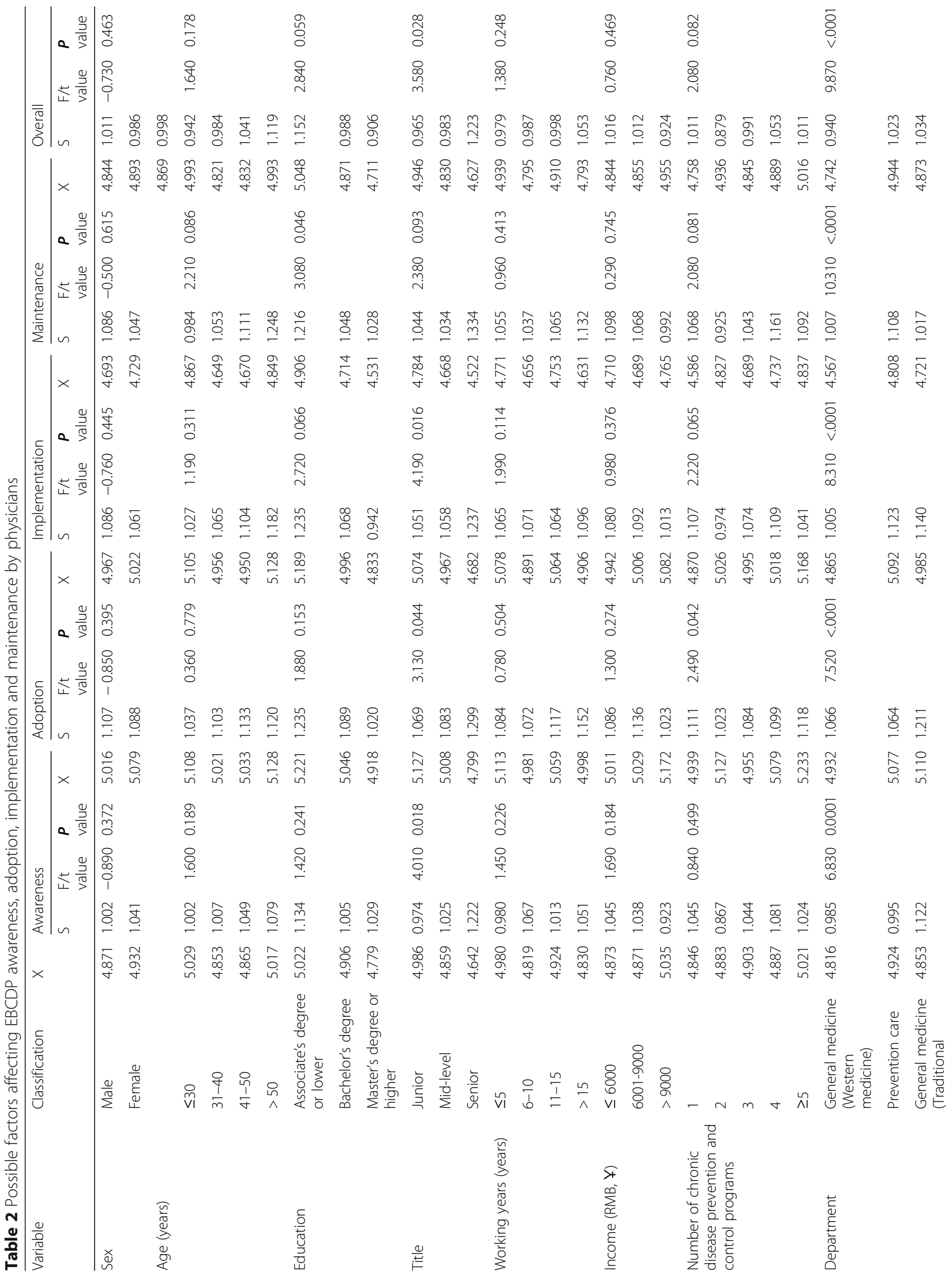




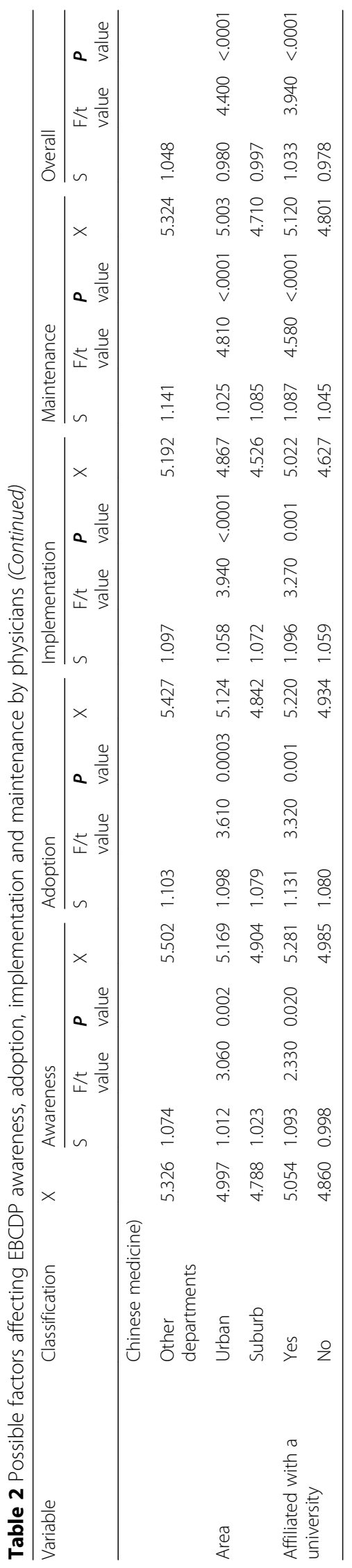


Table 3 Regression analysis of differences within various EBCDP aspects

\begin{tabular}{|c|c|c|c|c|c|c|c|c|c|c|c|c|}
\hline \multirow[t]{2}{*}{ Variable } & \multirow[t]{2}{*}{ Classification } & & \multicolumn{2}{|c|}{ Awareness } & \multicolumn{2}{|c|}{ Adoption } & \multicolumn{2}{|c|}{ Implementation } & \multicolumn{2}{|c|}{ Maintenance } & \multicolumn{2}{|l|}{ Overall } \\
\hline & & & $B$ & $\begin{array}{l}P \\
\text { value }\end{array}$ & $B$ & $\begin{array}{l}P \\
\text { value }\end{array}$ & B & $\begin{array}{l}P \\
\text { value }\end{array}$ & $B$ & $\begin{array}{l}P \\
\text { value }\end{array}$ & B & $\begin{array}{l}P \\
\text { value }\end{array}$ \\
\hline \multirow[t]{2}{*}{ Sex } & Male & Reference & & & & & & & & & & \\
\hline & Female & & 0.029 & 0.670 & 0.029 & 0.695 & 0.021 & 0.770 & 0.003 & 0.963 & 0.016 & 0.809 \\
\hline \multirow[t]{4}{*}{ Age (years) } & $\leq 30$ & Reference & & & & & & & & & & \\
\hline & $31-40$ & & -0.123 & 0.225 & -0.034 & 0.755 & -0.114 & 0.278 & -0.218 & 0.036 & -0.147 & 0.134 \\
\hline & $41-50$ & & -0.051 & 0.695 & 0.051 & 0.714 & -0.051 & 0.710 & -0.132 & 0.325 & -0.069 & 0.584 \\
\hline & $>50$ & & 0.185 & 0.376 & 0.223 & 0.320 & 0.205 & 0.347 & 0.103 & 0.630 & 0.162 & 0.422 \\
\hline \multirow[t]{3}{*}{ Education } & Associate's degree or lower & Reference & & & & & & & & & & \\
\hline & Bachelor's degree & & 0.052 & 0.691 & -0.006 & 0.965 & -0.009 & 0.949 & 0.038 & 0.777 & 0.021 & 0.868 \\
\hline & Master's degree or higher & & -0.122 & 0.469 & -0.180 & 0.320 & -0.227 & 0.196 & -0.178 & 0.306 & -0.182 & 0.263 \\
\hline \multirow[t]{3}{*}{ Title } & Senior & Reference & & & & & & & & & & \\
\hline & Junior & & 0.466 & 0.026 & 0.545 & 0.015 & 0.468 & 0.031 & 0.321 & 0.134 & 0.418 & 0.038 \\
\hline & Mid-level & & 0.323 & 0.043 & 0.345 & 0.043 & 0.394 & 0.018 & 0.199 & 0.224 & 0.293 & 0.057 \\
\hline \multirow{4}{*}{$\begin{array}{l}\text { Working years } \\
\text { (year) }\end{array}$} & $\leq 5$ & Reference & & & & & & & & & & \\
\hline & $6-10$ & & -0.122 & 0.347 & $-\overline{0} \cdot 101$ & 0.466 & $\overline{-}-221$ & 0.101 & $\overline{-} 0.091$ & 0.493 & $-\overline{0.131}$ & 0.291 \\
\hline & $11-15$ & & 0.013 & 0.939 & 0.012 & 0.948 & -0.041 & 0.814 & 0.057 & 0.742 & 0.017 & 0.917 \\
\hline & $>15$ & & 0.031 & 0.869 & 0.088 & 0.665 & -0.054 & 0.784 & 0.020 & 0.918 & 0.013 & 0.943 \\
\hline \multirow[t]{3}{*}{ Income (RMB, Ұ) } & $>9000$ & Reference & & & & & & & & & & \\
\hline & $\leq 6000$ & & -0.255 & 0.011 & -0.217 & 0.042 & -0.229 & 0.027 & -0.146 & 0.154 & -0.196 & 0.041 \\
\hline & 6001-9000 & & -0.247 & 0.011 & -0.204 & 0.049 & -0.159 & 0.113 & -0.175 & 0.078 & -0.187 & 0.045 \\
\hline \multirow{5}{*}{$\begin{array}{l}\text { Number of } \\
\text { programs }\end{array}$} & $\geq 5$ & Reference & & & & & & & & & & \\
\hline & 1 & & -0.173 & 0.079 & -0.284 & 0.007 & -0.292 & 0.004 & -0.225 & 0.025 & -0.244 & 0.010 \\
\hline & 2 & & -0.102 & 0.387 & -0.067 & 0.597 & -0.107 & 0.383 & 0.046 & 0.706 & -0.036 & 0.754 \\
\hline & 3 & & -0.081 & 0.473 & -0.237 & 0.050 & -0.132 & 0.261 & -0.099 & 0.392 & -0.127 & 0.244 \\
\hline & 4 & & -0.103 & 0.387 & -0.112 & 0.375 & -0.104 & 0.398 & -0.041 & 0.739 & -0.078 & 0.492 \\
\hline \multirow[t]{4}{*}{ Department } & $\begin{array}{l}\text { General medicine (Western } \\
\text { medicine) }\end{array}$ & Reference & & & & & & & & & & \\
\hline & Preventive care & & 0.113 & 0.191 & 0.138 & 0.134 & 0.229 & 0.011 & 0.217 & 0.014 & 0.191 & 0.021 \\
\hline & $\begin{array}{l}\text { General medicine (Traditional } \\
\text { Chinese medicine) }\end{array}$ & & 0.066 & 0.576 & 0.217 & 0.086 & 0.161 & 0.190 & 0.175 & 0.148 & 0.161 & 0.157 \\
\hline & Other departments & & 0.505 & $<.0001$ & 0.562 & $<.0001$ & 0.551 & $<.0001$ & 0.588 & $<.0001$ & 0.561 & $<.0001$ \\
\hline \multirow[t]{2}{*}{ Area } & Urban & Reference & & & & & & & & & & \\
\hline & Suburban & & -0.150 & 0.047 & -0.148 & 0.066 & -0.171 & 0.029 & -0.237 & 0.002 & -0.192 & 0.008 \\
\hline \multirow{2}{*}{$\begin{array}{l}\text { Affiliated with a } \\
\text { university }\end{array}$} & Yes & Reference & & & & & & & & & & \\
\hline & No & & -0.156 & 0.077 & -0.241 & 0.011 & -0.224 & 0.015 & -0.321 & 0.0001 & -0.257 & 0.003 \\
\hline
\end{tabular}

countries. It has been found that among US and European public health practitioners, $56-64 \%$ of chronic disease prevention interventions currently in use are evidence-based [37], while quantitative estimates of EBCDP use and possible factors influencing that use in lower- and middleincome countries are rare [38]. In this study, we evaluated physician EBCDP practice and possible personal and organizational factors affecting that practice in Shanghai, China.
The results indicate that physicians perceived their EBCDP adoption and implementation to be strong. However, they had relatively lower levels of awareness and maintenance with respect to EBCDP. This outcome is in accordance with Shi et al.'s (2019) qualitative study in China, which found that physicians integrate evidence into chronic disease prevention practices poorly [39], as suggested by the lack of a well-developed evidence base and low levels of physician awareness, adoption, 
implementation, and adequate maintenance of EBCDP; similar results have been observed in other Asian and developing countries $[40,41]$. For instance, Jirawattanapisal et al. compared healthcare data collection, sharing, and use in Thailand, Mainland China, South Korea, Taiwan, Japan, and Malaysia and found that many data are not used. One can speculate that obtaining persuasive evidence and data accessibility are important issues to be addressed in developing countries [41]. Realizing the importance of using evidence, China has gradually implemented evidence-based approaches to target several common chronic diseases, in part by making data more available. The Health Ministry has issued a series of technical guidance manuals for the prevention and treatment of diseases in $\mathrm{CHCs}$, including cardiovascular diseases, type II diabetes, chronic hepatitis B, and tumours [42, 43]. Additionally, we found that the maintenance of EBCDP, that is, the extent to which a program becomes institutionalized as part of routine organizational practices and policies, was not a particular problem in China, unlike in other developing and developed countries [21, 22].

Concerning the specific factors that influence EBCDP practice, we analysed the effect of physician demographics. First, physicians who were younger and held junior titles were more likely to practice EBCDP. This finding may be explained by the availability of evidence-based concepts and training courses, as this population may have had more exposure to EBCDP. Additionally, these groups of physicians were relatively new to their work and typically more likely than their colleagues with longer tenure to acquire new knowledge and adopt new methods. Second, we found that those who participated in only one chronic disease prevention and control program were less inclined to adopt, implement and maintain EBCDP, reflecting that the programs provided by the government can directly increase physician consciousness and practice of EBCDP. This finding is consistent with Hannon's (2010) study that found that program participation could successfully change practitioner behaviour [15].

Regarding organizational barriers, first, it was interesting to note that general practitioners (GPs) had lower levels of awareness of EBCDP than other physicians. In China, GP training differs from that of public healthcare physicians and physicians working in medical technology and rehabilitation departments. Therefore, the standardized and on-the-job training courses for GPs should include more evidence-based elements in China. Additionally, in China, it is common that although GPs are required to assume responsibility for chronic disease prevention and control, many GPs focus more on disease treatment [44]. Second, in this study, physicians from $\mathrm{CHCs}$ in urban areas had greater awareness of EBCDP than those from $\mathrm{CHCs}$ in suburban areas. This finding may be influenced by organizational management practices and policy factors. Budd et al. confirmed that organizational culture greatly influences EBCDP [25]. In addition, EBCDP practice was strongly influenced by the incentive policy of the local health government. In urban areas, there may be more investment in training programs or chronic disease prevention programs involving EBCDP [25]. Third, the results indicated that if a $\mathrm{CHC}$ is affiliated with a university, its physicians might be able to access more evidence-based resources and have greater opportunity to collaborate with researchers. Therefore, their awareness of EBCDP is greater. In China, particularly in large cities, many $\mathrm{CHCs}$ have established cooperative relationships with universities with regard to academic and clinical issues. This finding also suggests that to increase physician EBCDP practice, more training should be provided. In the US, EBDM training courses have been conducted in both Kansas and Mississippi to address gaps in competencies among public health practitioners. Evidence-based public health training has been found to be an effective method of integrating new knowledge and skills into the public health workforce $[37,45]$. Such training can include programs focused on specific EBDM skills or on incentives and policies that could affect the organizational culture in a workplace [46].

\section{Limitations}

This study has several limitations. First, the analysed data were self-reported, which may result in bias due to the ability of a participant to recall and/or report the requisite information. Survey respondents were provided a standard definition of EBDM before completing the questionnaire. However, the results should still be interpreted with caution given that they were self-reported. Second, regarding the study design, although the sample $\mathrm{CHCs}$ were randomly chosen in the cross-sectional study, the participant sample was not well randomized. Participants were selected at each $\mathrm{CHC}$ mainly with the assistance of administrators. As a result, the age of our sample was relatively young. Third, because the sample was chosen from CHCs in Shanghai, the survey may not be representative of other cities. Fourth, since the study focused on personal and organizational-level barriers, additional research on the political and sociocultural barriers that influence EBCDP is required.

\section{Conclusion}

This study provides robust quantitative evidence regarding the EBCDP practice of physicians from $\mathrm{CHCs}$ with various personal and organizational characteristics, respectively. The $\mathrm{CHC}$ physicians perceived their awareness and maintenance of EBCDP to be relatively low. Those who had participated in fewer chronic disease prevention and control programs, worked in general practice (Western medicine), were from suburban $\mathrm{CHCs}$, 
and were at $\mathrm{CHCs}$ not affiliated with universities exhibited lower EBCDP-related outcomes. More methods should be developed to improve these participants' EBCDP practice and to stimulate the use of EBCDP for chronic disease prevention and other public health priorities. This study represents an important step in this direction and identifies several potential avenues for future research.

\section{Abbreviations}

EBDM: Evidence-based decision-making; CHCs: Community healthcare centre; EBCDP: Evidence-based chronic disease prevention

\section{Acknowledgements}

We sincerely acknowledge and appreciate the assistance of the community healthcare centres in Shanghai for their help in collecting the data.

\section{Authors' contributions}

Experiment conception and design: FF, ZXW and JWS. Data analysis: FF and CC. Contribution of reagents/materials/analysis tools: CC, DLS, ZHY, XL, and HNZ. Writing: FF and JWS. Revision: ZXW and DHY. All individuals listed in this section have read and approved the manuscript.

\section{Funding}

The design of this study, which involved prior investigation, was supported by Shanghai Excellent Young Talents Project in Health Systems (2018YQ52). Data extraction was financially funded by the Natural Science Foundation of China $(71603182,71774116)$. The analysis and interpretation of the data under the guidance of statisticians was supported by grants from the National Key R\&D Program of China (2018YFC1314700). The paper's writing and revision, including language improvement, were sponsored by the Shanghai Pujiang Program (2019PJC072), Soft Project of Coronavirus Prevention and Control (2020RK38) and Medicine and Engineering Interdisciplinary Research Fund of Shanghai Jiao Tong University (YG2020YQ06).

\section{Availability of data and materials}

The data set supporting the conclusions of this article is available from the corresponding author on reasonable request.

\section{Ethics approval and consent to participate}

Ethical approval was obtained from the Research Ethics Committee of the School of Medicine, Tongji University (ref: LL-2016-ZRKX-017). Written consent was allowed according to the Ethics committee. The data were collected anonymously from the participants, and written consent was obtained from each participants.

\section{Consent for publication}

Not applicable.

\section{Competing interests}

The authors declare that no conflict of interest exists.

\footnotetext{
Author details

${ }^{1}$ Yangpu Hospital affiliated to Tongji University School of Medicine, Shanghai 200090, China. ${ }^{2}$ Academic Department of General Practice, Tongji University School of Medicine, Shanghai 200090, China. ${ }^{3}$ School of Public Health, Shanghai Jiaotong University School of Medicine, Shanghai 200025, China. ${ }^{4}$ General Practice Center, Nanhai Hospital, Southern Medical University, Foshan 528244, China. ${ }^{5}$ Shanghai General Practice and Community Health Development Research Center, Shanghai 200090, China. 'Shanghai Jing'an District Jiangning Road Community Health Service Center, Shanghai 200041, China. ${ }^{7}$ Shanghai Fenglin Community Health Service Center, Shanghai 200000, China. ${ }^{8}$ Navy 971 Hospital, Qingdao 266071, China.
}

Received: 14 January 2020 Accepted: 7 July 2020

Published online: 22 July 2020

\section{References}

1. GBD 2015 Disease and Injury Incidence and Prevalence Collaborators. Global, regional, and national incidence, prevalence, and years lived with disability for 328 diseases and injuries for 195 countries, 1990-2016: a systematic analysis for the global burden of disease study 2016. Lancet. 2016:388:8-14.

2. NCD Countdown 2030 Collaborators. NCD countdown 2030: worldwide trends in non-communicable disease mortality and progress towards sustainable development goal target 3.4. Lancet. 2018;392:1072-88.

3. Zhou MG, Wang HD, Zeng XY, Yin P, Zhu J, Chen WQ, et al. Mortality, morbidity, and risk factors in China and its provinces, 1990-2017: a systematic analysis for the global burden of disease study 2017. Lancet. 2019:394(10204):1145-58.

4. Allen P, O'Connor JC, Best LA, Lakshman M, Jacob RR, Brownson RC. Management practices to build evidence-based decision-making capacity for chronic disease prevention in Georgia: a case study. Prev Chronic Dis. 2018:15:E92. https://doi.org/10.5888/pcd15.170482.

5. Parks RG, Tabak RG, Allen P, Baker EA, Stamatakis KA, Poehler AR, et al. Enhancing evidence-based diabetes and chronic disease control among local health departments: a multi-phase dissemination study with a stepped-wedge cluster randomized trial component. Implement Sci. 2017; 12(1):122. https://doi.org/10.1186/s13012-017-0650-4.

6. Allen P, Sequeira S, Jacob RR, Hino AA, Stamatakis KA, Harris JK, et al. Promoting state health department evidence-based cancer and chronic disease prevention: a multi-phase dissemination study with a cluster randomized trial component. Implement Sci. 2013;8:141. https://doi.org/10.1186/1748-5908-8-141.

7. Zaza S, Briss PA, Harris KW. The guide to community preventive services: what works to promote health? New York: Oxford University Press; 2005.

8. Briss PA, Brownson RC, Fielding JE, Zaza S. Developing and using the guide to community preventive services: lessons learned about evidence-based public health. Annu Rev Public Health. 2004;25:281-302.

9. Kerner JF, Guirquis-Blake J, Hennessy KD, Brounstein PJ, Vinson C, Schwartz $\mathrm{RH}$, et al. Translating research into improved outcomes in comprehensive cancer control. Cancer Causes Control. 2005:16(Supplement 1):27-40.

10. Shi J, Shi L, Geng J, Liu R, Gong X, Bo X, et al. Status of evidence-based chronic diseases prevention implementation in Shanghai, China: a qualitative study. Int J Health Plann Manag. 2019;34(3):912-25.

11. Health Evidence. https://www.healthevidence.org/. Accessed Nov 31, 2018

12. Cochrane. http://www.cochrane.org/. Accessed Nov 31, 2018.

13. Cochrane Public Health Group. http://www.ph.cochrane.org/. Accessed Nov 31, 2018.

14. Jacobs JA, Clayton PF, Dove C, Funchess T, Jones E, Perveen G, et al. A survey tool for measuring evidence-based decision making capacity in public health agencies. BMC Health Serv Res. 2012;12:57. https://doi.org/10. 1186/1472-6963-12-57.

15. Hannon PA, Fernandez ME, Williams RS, Mullen PD, Escoffery C, Kreuter MW, et al. Cancer control planners' perceptions and use of evidence-based programs. J Public Health Manag Pract. 2010;16:E1-8. https://doi.org/10 1097/PHH.0b013e3181b3a3b1.

16. Sosnowy CD, Weiss LJ, Maylahn CM, Pirani SJ, Katagiri NJ. Factors affecting evidence-based decision making in local health departments. Am J Prev Med. 2013:45(6):763-8.

17. Poehler AR, Parks RG, Tabak RG, Baker EA, Brownson RC. Factors facilitating or hindering use of evidence-based diabetes interventions among local health departments. J Public Health Manag Pract. 2019. https://doi.org/10. 1097/PHH.0000000000001094.

18. Mazzucca S, Parks RG, Tabak RG, Allen P, Dobbins M, Stamatakis KA, et al. Assessing organizational supports for evidence-based decision making in local public health departments in the United States: development and psychometric properties of a new measure. J Public Health Manag Pract. 2019;25(5):454-63.

19. Armstrong $R$, Waters $E$, Dobbins $M$, Anderson L, Moore L, Petticrew M, et al. Knowledge translation strategies to improve the use of evidence in public health decision making in local government: intervention design and implementation plan. Implement Sci. 2013:8:1-10.

20. Leeman J, Teal R, Jernigan J, Reed JH, Farris R, Ammerman A. What evidence and support do state-level public health practitioners need to address obesity prevention. Am J Health Promot. 2014;28:189-96. 
21. Jacobs JA, Dodson EA, Baker EA, Deshpande AD, Brownson R. Barriers to evidence-based decision making in public health: a National Survey of chronic disease practitioners. Public Health Rep. 2010;125:736-42.

22. Dodson EA, Baker E, Brownson R. Use of evidence-based interventions in state health departments: a qualitative assessment of barriers and solutions. J Public Heal Manag Pr. 2010;16:E9-15.

23. Armstrong R, Pettman T, Burford B, Doyle J, Waters E. Tracking and understanding the utility of Cochrane reviews for public health decisionmaking. J Public Heal (United Kingdom). 2012;34:309-13.

24. Pettman TL, Armstrong R, Pollard B, Evans R, Stirrat A, Scott I, et al. Using evidence in health promotion in local government: contextual realities and opportunities. Heal Promot J Aust. 2013;24:72-5.

25. Budd EL, de Ruyter AJ, Wang Z, Sung-Chan P, Ying X, Furtado KS, et al. A qualitative exploration of contextual factors that influence dissemination and implementation of evidence-based chronic disease prevention across four countries. BMC Health Serv Res. 2018;18(1):233. https://doi.org/10.1186/ s12913-018-3054-5.

26. Australian Health Promotion Association. Core competencies for health promotion practitioners. [http://www.healthpromotion.org.au/images/ stories/pdf/core\%20competencies\%20for\%20hp\%20practitioners.pdf].

27. Health Protection Agency. 2010 annual report and accounts. [http://www. hpa.org.uk/web/HPAwebFile/HPAweb_C/1274093575390].

28. Institute of Public Health in Ireland: IPH annual review: 2010. [http://www. publichealth.ie/sites/default/files/documents/files/PH\%20Annual\%2 OReview\%202010.pdf].

29. Public Health Agency of Canada: Strategic plan 2007-2012. [http://Www. phac-aspc.gc.ca/publicat/2007/spps/pdfs/PHAC_StratPlan_E_WEB.pdf].

30. Shanghai Health and Family Planning Commission. Three-year Action Plan for strengthening the Construction of Public Health system in Shanghai (2015-2017). http://www.shanghai.gov.cn/nw2/nw2314/nw2319/nw12344/ u26aw45010.html. Accessed 2019-09-21.

31. Dreisinger ML, Boland EM, Filler CD, Baker EA, Hessel AS, Brownson RC. Contextual factors influencing readiness for dissemination of obesity prevention programs and policies. Health Educ Res. 2012;27(2):292-306.

32. Glasgow RE, Vogt TM, Boles SM. Evaluating the public health impact of health promotion interventions: the RE-AIM framework. Am J Public Health. 1999;89(9):1922-7.

33. Rogers EM. Diffusion of innovations. New York: Free Press; 2003.

34. Kessler RS, Purcell EP, Glasgow RE, Klesges LM, Benkeser RM, Peek CJ. What does it mean to "employ" the RE-AIM model? Eval Health Prof. 2013;36:4466. https://doi.org/10.1177/0163278712446066.

35. Cai LQ, Hou J, Lu XJ. Effectiveness evaluation of on-the-job training for general practitioners in rural community health service center in the outlying suburbs of Shanghai. Chinese J Gen Pract (Chinese Journal). 2019;17(2):256-8.

36. Deng XL. A model for medical university-affiliated hospitals joining community health services and its evaluative index system: Dissertation of Southern Medical University (Chinese article); 2009.

37. Dreisinger M, Leet TL, Baker EA, Gillespie KN, Haas B, Brownson RC. Improving the public health workforce: evaluation of a training course to enhance evidence-based decision making. J Public Heal Manag Pr. 2008;14: 138-43. https://doi.org/10.1097/01.PHH.0000311891.73078.50.

38. Budd EL, Ying X, Stamatakis KA, de Ruyter AJ, Wang Z, Sung P, et al. Developing a survey tool to assess implementation of evidence-based chronic disease prevention in public health settings across four countries. Front Public Health. 2019;7:152. https://doi.org/10.3389/fpubh.2019.00152 eCollection 2019.

39. Shi J, Jiang C, Tan D, Yu D, Lu Y, Sun P, et al. Advancing implementation of evidence-based public health in China: an assessment of the current situation and suggestions for developing regions. Biomed Res Int. 2016; 2016:2694030. https://doi.org/10.1155/2016/2694030 Epub 2016 Aug 14.

40. Lee EJ. Needs assessment for the computer-interpretable hypertension guideline at public health centers in Korea. In: Kuhn KA, Warren JR, Leong TY, editors. Medinfo. 2007. Proceedings of the 12th world congress on health (medical) informatics-building sustainable health systems. Amsterdam: IOS Press; 2007. p. 1455.

41. Jirawattanapisal T, Kingkaew P, Lee TJ, Yang MC. Evidence-based decisionmaking in Asia-Pacific with rapidly changing health-care systems: Thailand, South Korea, and Taiwan. Value Health. 2009;12(Suppl 3):S4-S11. https://doi. org/10.1111/j.1524-4733.2009.00620.x.
42. Wang ZX, Jiang $C H$, Liu R, Zhang $L$, Zhang Y, Chen MX, et al. Analysis of necessity about evidence-based concepts into chronic disease prevention and control. Chinese Med (Chinese Journal). 2013;16(8A):2627-9.

43. Liang Y. Study on the Government's responsibility in the management of the chronic non-communicable diseases in China: Shandong University; 2014.

44. Jiang B. Enlightenment and suggestion on epidemic characteristics and prevention and treatment of stroke in China for general medical service. Chinese Gen Med (Chinese Journal). 2019;30:3653-61.

45. Franks AL, Brownson RC, Bryant C, Brown KM, Hooker SP, Pluto DM, et al. Contributions to updating the public health workforce through training. Prev Chronic Dis. 2005:2(2):A26.

46. Aarons G, Horowitz J, Dlugosz L, Ehrhart M. The role of organizational processes in dissemination and implementation research. In dissemination and implementation research in health: translating science to practice. Edited by: Brownson RC, Colditz GA, proctor EK. New York: Oxford University Press; 2012.

\section{Publisher's Note}

Springer Nature remains neutral with regard to jurisdictional claims in published maps and institutional affiliations.
Ready to submit your research? Choose BMC and benefit from:

- fast, convenient online submission

- thorough peer review by experienced researchers in your field

- rapid publication on acceptance

- support for research data, including large and complex data types

- gold Open Access which fosters wider collaboration and increased citations

- maximum visibility for your research: over $100 \mathrm{M}$ website views per year

At BMC, research is always in progress.

Learn more biomedcentral.com/submissions 